\title{
Experts, Fools, and Why the Budworm Problem Seems So Complex
}

\author{
G. L. Baskerville
}

The notion that there are experts on the budworm problem is a dangerous myth. It implies that these people comprehend the problem in all its dimensions and this is patently impossible. As a first step in reaching rational decisions with respect to budworm/forest management in New Brunswick we need recognition of the counter-myth that no such people exist. Don't misunderstand. There are experts on budworm biology, there are experts on the forest, there are experts on natural resource economics, there are experts on control techniques, there are experts on the environmental effects of spraying, and there are experts on the public health issues. But few, if any, of these would claim full comprehension within their field and none, to my knowledge, claims to have a working understanding of all fields involved in the budworm/forest management problem.

We have experts on parts of the problem but not on the problem itself. Why is this a concern? The classic media interview, and indeed most casual discussion, with an "expert" begins in the area of the person's competence and inevitably leads to a question such as "O.K., now what does New Brunswick do in 1977?". The "expert" has two choices: he can refuse to answer and be seen to avoid the question (an arch sin) or he can attempt to answer. Being human, most attempt a qualified answer. Unfortunately, most listeners fail to recognize the critical importance of the qualifications, resulting in the implication, to them, that the expert's comprehension extends to all facets of the problem, that he understands the needs and desires of the people of New Brunswick, and that he has weighed all factors and can pronounce the course of action that best balances these needs. That such an implication is ludicrous appears to have escaped the media entirely. Indeed, their approach to the budworm problem systematically enforces it to the ultimate confusion of just about everybody.

\section{"Disagreement" Among Experts}

We hear much of the disagreement among experts about budworm/forest management and this is used to justify almost any line of action or inaction. We should understand this disagreement for what it is. Within a given field, such as any of those listed above, the experts have a surprising level of agreement. They may earnestly debate technique or points of analysis, but when it comes to the essential meaning of their work there is very little disagreement. How, then, can they so readily be seen to disagree? If the contentious statements are examined carefully, it will be seen that in virtually every case they arise when the ex- pert steps outside his real area of knowledge and makes a value judgement. As individuals, we value things differently and our understanding of the world around us is different. Therefore, it should not be surprising that these value judgements expressed by experts show decided disagreement; it is just that the individuals place different values on various factors.

Although it is illogical to do so, we often use the fact that a person is an expert in one field to infer that he is an expert in many fields. This makes opinions of experts exceedingly dangerous to use. However, within limits, these opinions can be very valuable, and hence should be respected. To illustrate the situation let us be presumptuous and arbitrarily divide the budworm problem into six broad issues.

1. The biological dynamics of the budworm population over time and across the New Brunswick forest. This is what we want to control.

2. The biological dynamics of the forest over time and across the province.

3. The dynamics of supply and demand in the forest-based industries. Our interest in controlling the insect stems from a desire to have economic stability.

4. The relatives aesthetic value of dead trees, red trees, green trees, and cutover, and how this influences tourism and our appreciation of our environment.

5. The very broad area of side-effects in the natural world resulting from our efforts to control the budworm and harvest the forest.

6 . The public health issues related to budworm control and harvesting. Biologically one could argue that these are part of (5), but since our view of the world sets humans apart, we must treat these issues separately.

This division is neither definitive nor all-inclusive, but is given only to show the broad range of issues involved. Even the casual reader will understand that each of these six issues covers an exceedingly large area of scientific knowledge and that few experts would claim full comprehension even within one area. Again, don't misunderstand. There are experts in these areas and, fortunately for New Brunswick, some of the most qualified ones are readily available to us. This may seem to be the classic scientific "cop-out" that the "problem is complex", and perhaps it is. The point is, that it requires half a lifetime to gain expertise in one of these areas and people who do this successfully will, as a side-effect, gain the realization that other issues are just as difficult to unravel and that their understanding of these other areas is necessarily superficial. 
The difficulty here is that so many factors are linked together in so many ways. We look at a natural resource situation and intuitively feel the answer is straightforward and make our decision. One need only scan the current literature on environmental problems to gauge the kind of trouble this ignorance of linkage has brought us.

\section{Factors Not Isolated}

We tend to isolate our considerations of factors (we even set up separate government departments for them), but in the natural world they are not isolated. Their interrelationship is at least as complicated as shown in Figure 1, where an arrow means that action in one area causes impacts in another. The fact that we recognize that the problem embraces these diverse concerns is a good sign. That we work so hard to ignore this complexity is the root of the public controversy over budworm/forest management. And we do work hard at it. We all look for the conclusion first and often don't even bother to read the reasoning behind the conclusion. We insist, via the media, on having simple answers - on having the "expert" in entomology, environment, economics, public health, or what-have-you, give the overall decision. This, despite the fact that, on careful thought, we know that a person who is competent in one of these areas clearly cannot be competent in the others. It is small wonder, then, that budworm/forest management evokes such a wide range of "right decisions" for a given situation. This is because every one of these "right decisions" is based on an inadequate appreciation of the problem as a whole.

None of the experts from any of the areas of concern should be allowed a dominant role in resource decision-making. The dominant-role approach ignores linkages and is precisely how we have created the environmental difficulties that so beset us today. The contribution of the expert should be strictly limited in every case to provid- ing factual information, within his field of competence, on the various alternative decisions that are open and their probable outcomes.

The actual choice of decision must rest with those with the responsibility to balance all the factors and choose the course that is most appropriate for New Brunswick. Clearly the decisionmaker will not have expertise in the various areas of concern - he is expert at balancing the multitudinous and competitive desires of the people of New Brunswick. This is explicitly a matter of value judgement. Presented with expert information that shows that no decision will be without social problems (and most certainly none will) the decisionmaker must gauge the desires of society, assign relative value to the various issues, and reach the decision that best reflects the desired benefits to the people.

In our society the responsible person is the minister or, in major cases, the cabinet. They alone are responsible and, by definition, all other proposed decisions are from people who cannot be held responsible for the decision. This does not necessarily imply that these volunteered decisions are irresponsible, but only that those who put them forward are in a position of never being held responsible for the results of the decision.

\section{Decision-Maker Needs Adequate Facts}

To get the "best" decision for New Brunswick on any natural resource consideration including budworm/forest management we must ensure that adequate facts are presented to the decisionmaker and that he understands their short- and long-term implications. We can, and should, be vociferous about what considerations should enter the decision, and about what weight we feel they should be given, for this is how we influence the decision-making process in a democratic society. To avoid confusion, these expressions should be factual or, where value judgements are necessarily involved, stress the values to be con-

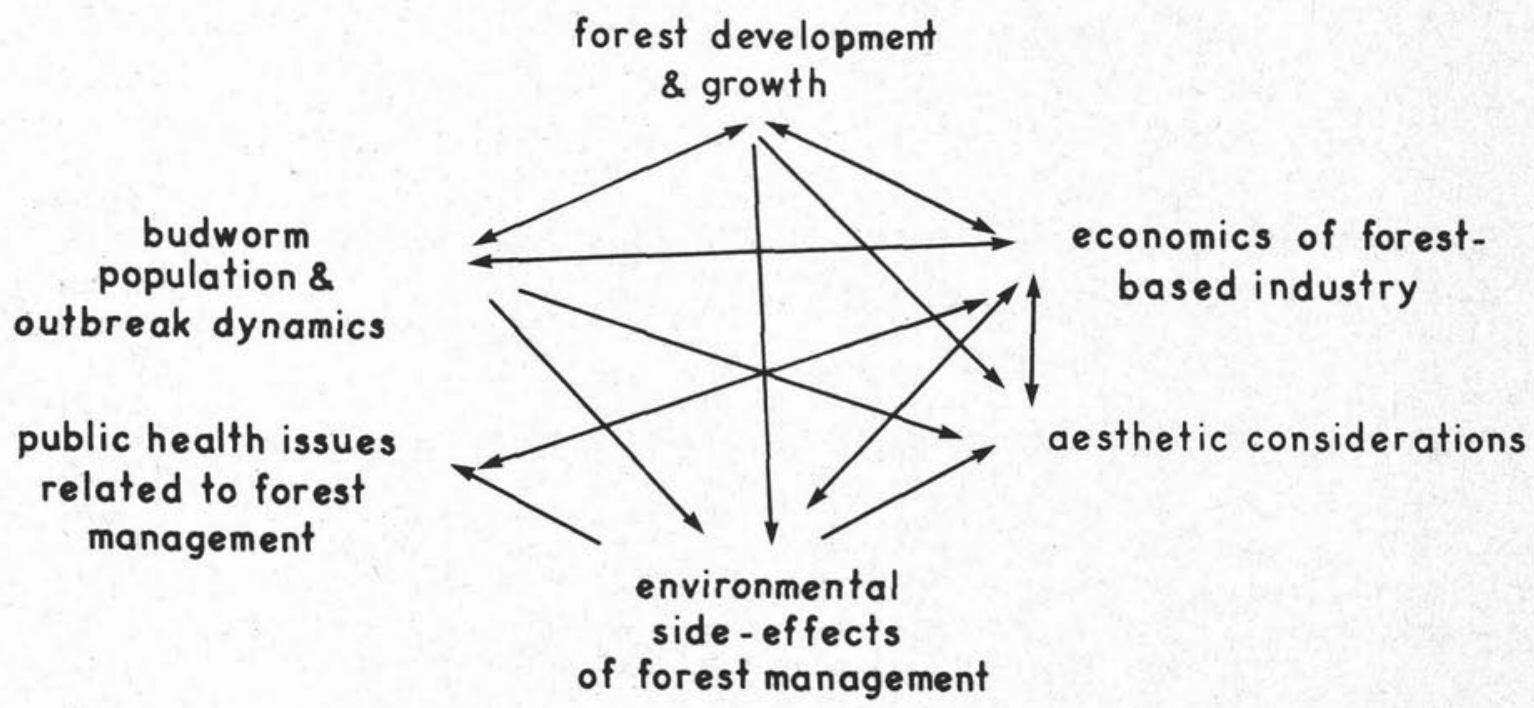

Fig 1. A schematic presentation of some broad issues involved in decision-making with respect to budworm/forest management.

12 February 1978 The Forestry Chronicle 
sidered. We should be vigilant in exposing advice from experts (or from pseudo-experts) that contains value judgement masquerading as fact. Whenever anybody, expert or otherwise, advises on what the decision should be, as opposed to advising on what factors should enter the decision and with what weight, they are pre-empting the decision-maker's role and are displaying the arrogance of a "know it all". Such "experts" who, by implication, claim to understand the full range of considerations and to have perceived the desires of the people of New Brunswick and balanced the two to give the "right" decision are dangerous fools. And those who would listen to them are deluded.

The problem is complex, but if it seems incomprehensible and insolvable it is only because the all-important function of information distribution has been tackled illogically. New Brunswick has available the expertise to deal with all the issues of the problem in a realistic way. If the media and the various protagonists can insist on facts, where these are appropriate, and limit the application of value judgements to the appropriate level of consideration, there is no apparent reason why New Brunswick cannot achieve clear and effective resource decisions.

(Reprinted from UNB Forestry Focus) Vol. 2 No. 2.

Some Comparative Data on Canadian Forest Products Industry and Fishing Industry

Wage Earners

(December, 1976 - Statistics Canada

Cat. No. 72-002)

Fish Products Mfg.

Wood Products Mfg.

(Not including landing)

Pulp \& Paper Mfg.

92,400

(Not including logging)

(Not including logging)

Value Added:

(1974 - Statistics Canada Cat. No. 61-202)

a) Primary Production

Fisheries

Forestry (logging)

291.2 million dollars

$1,220.8$ million dollars

b) Manufacturing (Processing)

Fish Processing

225.0 million dollars

Wood Mfg. (Lumber, Plywood, etc.) 1,708.9 million dollars

Sales:

Pulp \& Paper

3,033.7 million dollars

(1974 - Statistics Canada Cat. No. 61-207)

a) Primary Industries

Fishing

Forestry

55.4 million dollars

530.3 million dollars

b) Manufacturing

Fish Processing

Wood Mfg.

Pulp \& Paper

818.5 million dollars $3,868.8$ million dollars

$8,388.9$ million dollars

Value of Exports:

(1976 - Statistics Canada Cat. No. 65-004)

Fish \& Fish Products

579.4 million dollars

All Forest Products

6,501.8 million dollars

Corporate Income Taxes:

(1974 - Statistics Canada Cat. No. 61-207)

(Provision For Current Income Taxes)

Forestry (Logging)

Fishing \& Trapping

Fish Processing

Wood Mfg.

Pulp \& Paper

14.5 million dollars

.4 million dollars

7.0 million dollars

59.1 million dollars 306.8 million dollars 